\title{
Taming the purple monster
}

\author{
By Joe Jaros \\ Head, Instructional Services \\ Texas A\&M University
}

\author{
and Candace R. Benefiel
}

Humanities Reference Librarian

Texas A UM University

\section{Analyzing faculty responses to an informational brochure.}

$n$ the fall of 1988 the Sterling C. Evans Library of Texas A\&M University brought up a new automated catalog online, NOTIS. The old system, with its numerous shortcomings, including frequent and prolonged downtime and a lack of any subject searching capabilities, had been the focus of growing patron dissatisfaction. The widespread dislike of the system, bordering at times on hostility, had lead to a general distrust of the automated catalog. When the decision was made to implement a new system, one which promised far more flexibility in searching methods and increased reliability, the library recognized the need to publicize NOTIS effectively. Patrons, particularly faculty, needed to be made aware that a new system was available, and that it offered many advantages in comparison. For example, the introduction of subject and keyword searching capabilities, the latter employing Boolean logic, increased greatly the points of access available to users, but meant that users would need to acquire more sophisticated searching techniques in order to gain the most benefit from NOTIS.

The public relations campaign mounted to inform the university community about NOTIS contained initiatives directed toward several target audiences, including students, external support groups, and-perhaps most importantly-the faculty. The Public Relations Committee, working in cooperation with the bibliographic instruction librarians, felt that an informative and educational approach would be better for the faculty than catchy slogans and glitz. We therefore decided to develop an informational brochure that would not only describe the new system to the faculty, but would also give them a chance to seek out more information or instruction regarding NOTIS.

In the past, efforts at disseminating this type of information had been limited in scope and were usually directed toward new faculty or a smaller group of faculty, such as a department or two that might be interested in a new service. This time, however, we were faced with trying to contact the entire university faculty and numerous associated professional staff members and agency employees affiliated with the university, such as the Texas Agricultural Extension Service, the Texas Agricultural Experiment Station, and the Texas Engineering Extension Service. Altogether, the group numbered close to 4,000 . This presented problems not only in the logistics of the mailing, but also meant that the brochure itself needed to include information germane to the research needs of a very diverse audience.

Design and production of the brochure had to be approached carefully, with each step being reviewed and approved by the library administration to ensure that the content and style fulfilled the goal of the project. The resulting brochure was printed on orchid paper and consequently became more or less affectionately known as the "purple monster." It provided general background concerning the new system and gave brief instructions on the various searching modes available on 
NOTIS, with examples of basic search strategies. Printed on legal-sized paper and folded four times, the final panel consisted of a tear-away form with preprinted requests for further information or instruction on NOTIS.

Previous experiences in mailing brochures and other material had shown that bulk mailing to departments often resulted in overall poor distribution, forcing a reliance upon the clerical staff of each department, who could not always be trusted to distribute bulk mail material in a timely fashion. In addition, we felt that addressing each brochure individually in such a way that the mailing label would be on the tearsheet would make filling out the request sheet much simpler, and would allow us to respond to requests more easily. The next difficulty lay in finding a complete mailing list for faculty and professional staff. This was eventually overcome by purchasing a set of computer-produced mailing labels from the budget office of the university.

The tearsheet included blanks for requesting remote access directions, detailed searching guides, individual instruction, and demonstrations for classes or other groups. The form was in no way a formal questionnaire, and response was requested only if the addressee wanted additional information.

Although the major purpose of the mailing was to inform faculty about the new system and give them a chance to receive additional information and instruction regarding it, during the planning process another aspect arose. We realized that, through an analysis of the responses to the brochure, we were gathering information that might prove valuable. The analysis of the responses to the mailing would allow librarians to gauge what departments on campus displayed the most interest in the more sophisticated applications of the new system. After identifying the departments interested in various options for instruction and information, it should then become apparent which departments needed to be targeted for further contact and instruction regarding the system.

\section{Methodology}

The brochure was distributed via campus mail to all teaching faculty and most administrative and research personnel, with the major exception of the library faculty (who were already well-informed concerning the new system). The brochure included instructions for returning the tearsheet through campus mail, and also gave the Reference Department phone number for those who preferred calling in to returning the form.

The returned tearsheets were collected and responded to by the assistant head of instructional services, who also kept a running total on requests.
Once the main flow of responses had decreased, more formal statistics were compiled from the returned sheets and from phoned-in requests, many of which were directly prompted by the brochure. Statpal, a statistical software package for microcomputers, was used to generate descriptive statistics, which were then studied to ascertain patterns of response to the brochure.

\section{Results}

Five hundred fifty-five responses were received out of a mailing of almost 4,000 for a response rate of $14.55 \%$. The responses included 430 purple forms and 125 responses of other types such as phoned-in or in-person requests. Although the response rate appears quite low, it should be reiterated that the brochure was primarily intended as an introductory informational guide to the new system, a means of announcing to faculty the arrival of the new system and the increased searching capabilities now available at the Library. While the responses to the brochure in the form of returned tearsheets and telephone requests for further informational material lent themselves to quantitative measurement, no mechanism existed to measure informal response to the brochure. Many faculty, perhaps prompted by the brochure or other publicity visited the library to investigate NOTIS on their own initiative. Another factor in the response rate was that the tearsheet was closer in nature to an order form than a questionnaire, and solicited a response only if further information or instruction was desired.

Many of the respondents checked more than one option from the list on the tearsheet; perhaps the most frequent combination was a request for remote access instructions accompanied by a detailed searching guide. Of those responding, $90.3 \%$ wanted a detailed searching guide, $13.2 \%$ wanted individual instruction, and $8.1 \%$ wanted demonstrations of one type or another. Remote access instructions also proved quite popular, with $92.3 \%$ requesting remote access guides for either microcomputers and modems as well as hardwired terminals. The majority of the requests specified instructions for microcomputers with modems, while $6.7 \%$ preferred using a hardwired terminal (Figure 1). An additional $14.1 \%$ wanted information on access by both types of terminal setup. All those requesting remote access instructions were also sent a detailed searching guide, in order to aid them in using the system once they accessed it.

Upon analysis, responses from the individual colleges reveal a significant contrast (Figure 2). The response rate for individual colleges ranged from $23.2 \%$ for the College of Business to $8.3 \%$ for the College of Science. The Colleges of Geosciences, Engineering, Architecture, and Liberal Arts 


\section{REMOTE ACCESS REQUESTS: Computer Setups}

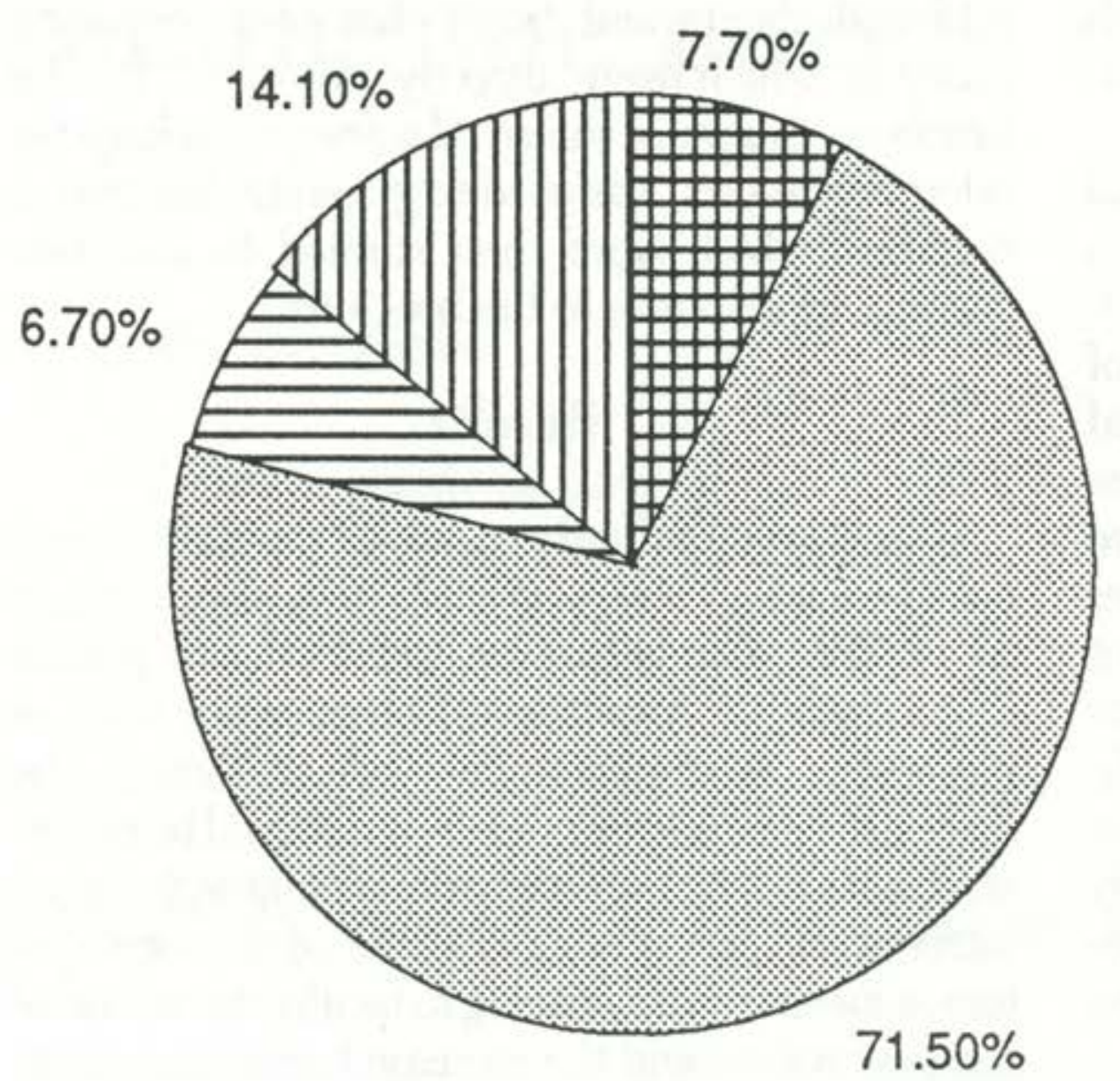

$\boxplus$ No Remote Access
㸚 Micro/Modem
$\boxminus$ Hardwired
$\square$ Both Types

Figure 1. Remote access requests.

had a return rate between $16 \%$ and $17 \%$, with Education and Agriculture following at about $14 \%$. One of the lower rates came from Veterinary Medicine, at $9.9 \%$. It should be noted, however, that the College of Veterinary Medicine has long had its own independent library.

Other descriptive statistics allowed for several comparisons of interest. While the percentage of responses requesting remote access guides was high from every college, the College of Business and the College of Science led the way with over
$97 \%$ of responses indicating an interest in remote access instructions (Figure 3). At the low end of range were the College of Education, at $75.9 \%$ and the College of Liberal Arts at $85.5 \%$. When looking at the requests for individual instruction sessions, however, the picture is quite different (Figure 4). Of those responding from the College of Education, $31 \%$ requested individual instruction, with the next highest rates being $17.6 \%$ and $17.8 \%$ from the College of Architecture and the University Administration. The college with the lowest rate of

\section{RESPONSES BY COLLEGE}

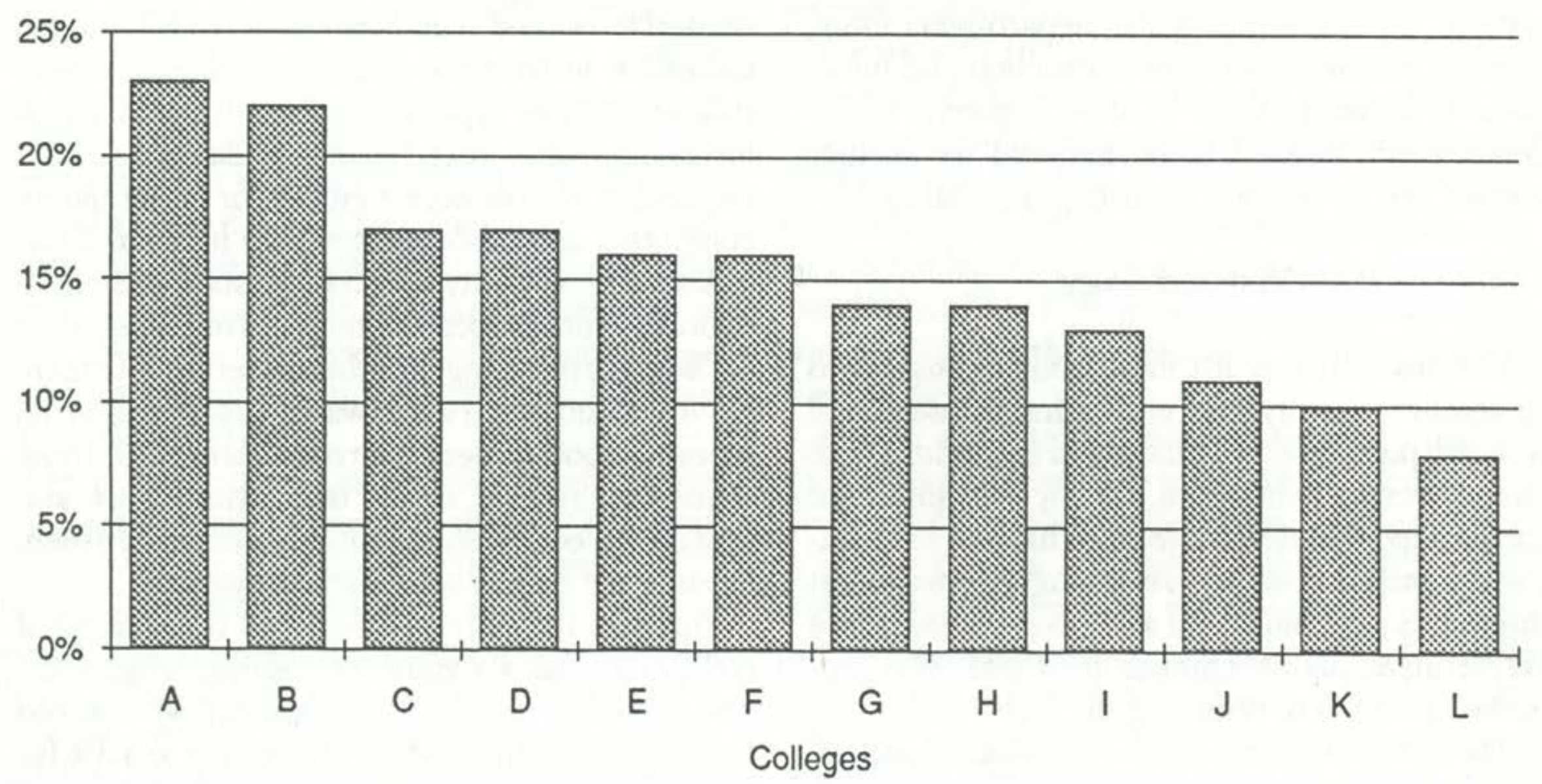

Figure 2. Response rate by college. See Appendix for graph key. 


\section{REMOTE ACCESS: Information Requests}

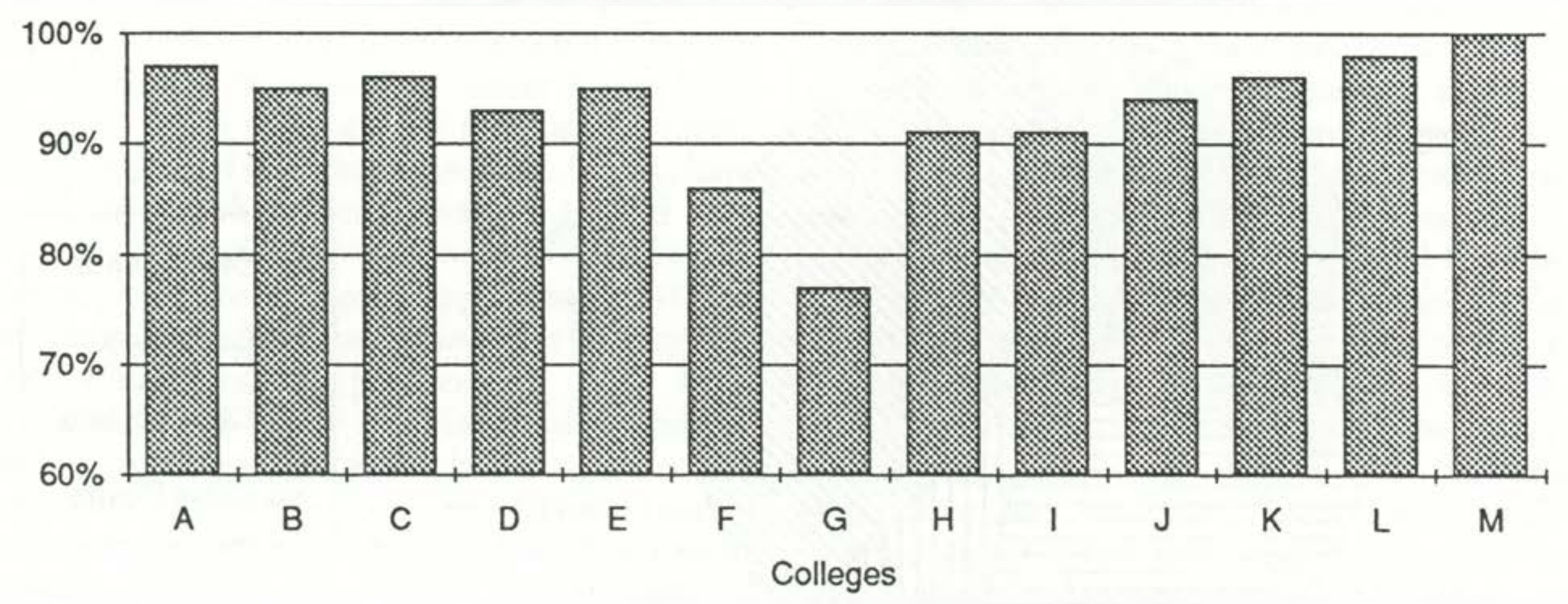

Figure 3. Information requests on remote access by college. See Appendix for graph key.

\section{INDIVIDUAL INSTRUCTION: Requests}

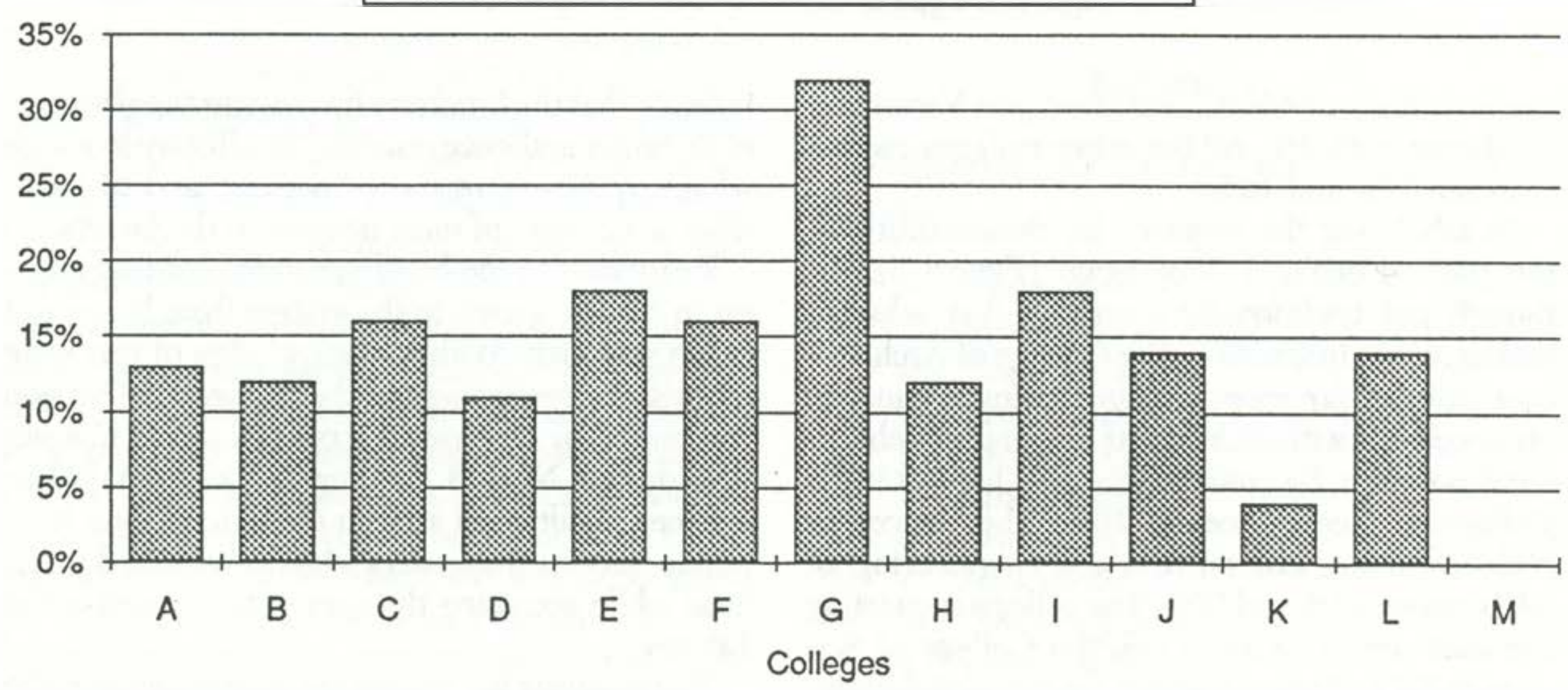

Figure 4. Information requests on individual instruction by college. See Appendix for graph key.

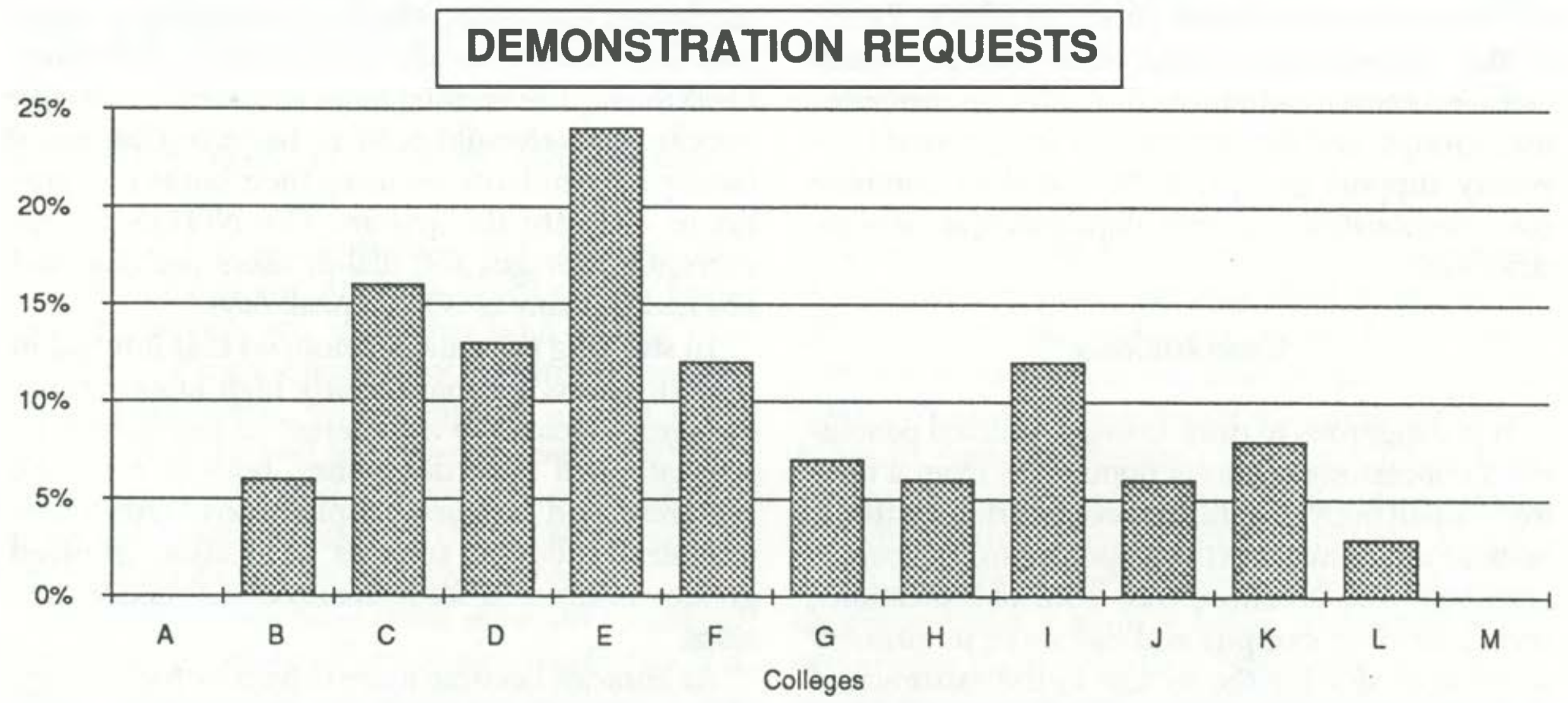

Figure 5. Requests for demonstrations by college. See Appendix for graph key. 


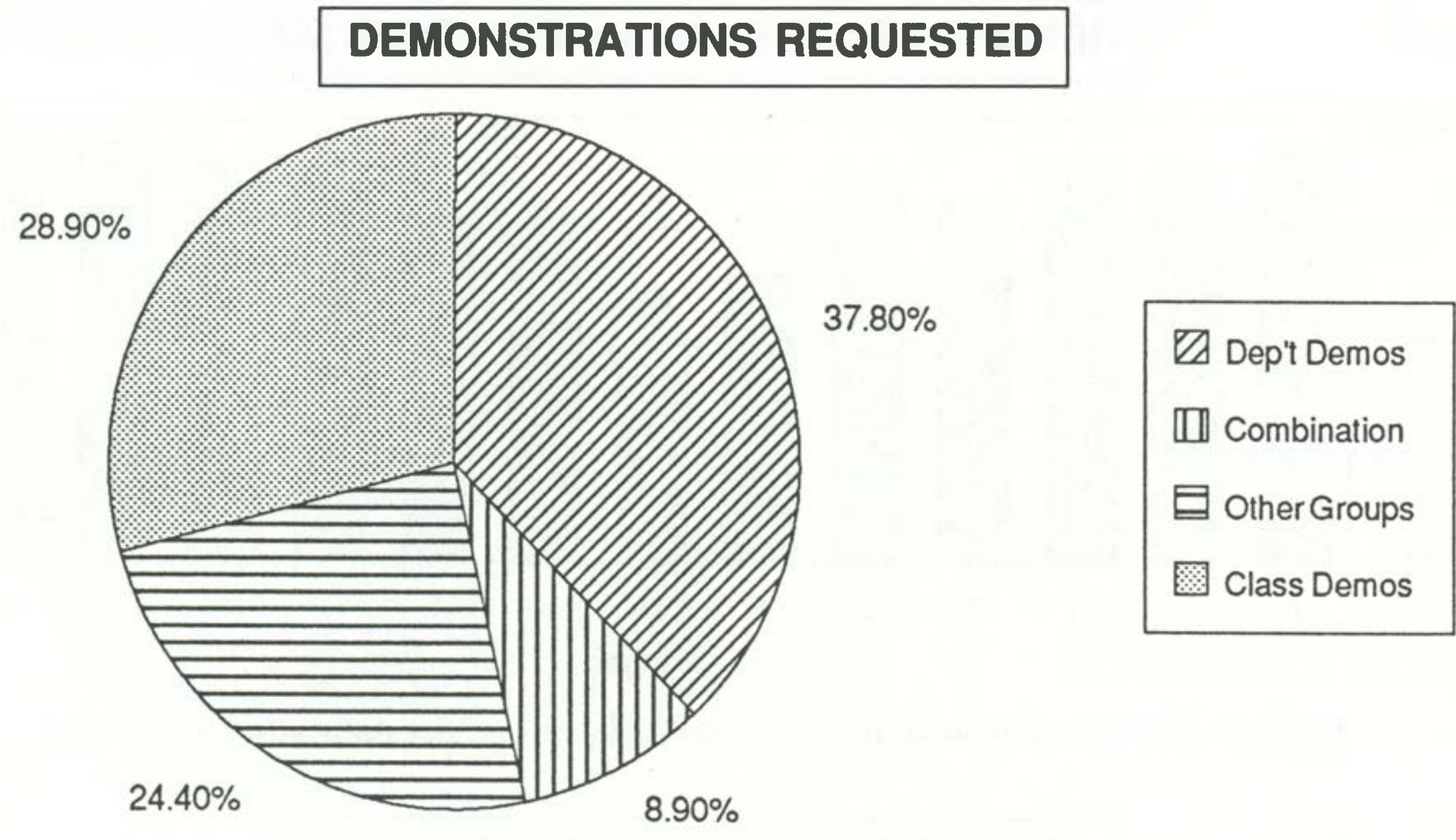

Figure 6. Type of demonstrations requested.

requests for individual instruction was Veterinary Medicine, with $4 \%$. All the other colleges ranged between $10 \%$ and $16 \%$.

In tabulating the requests for demonstrations, the pattern changes once again (Figure 5). Although not traditionally a college that asks for bibliographic instruction, the College of Architecture desired far more demonstrations than any other college, with $23.5 \%$ of its respondents choosing this option. By contrast, the next highest is the College of Geosciences at $16 \%$. The University Administration, Liberal Arts and Engineering all fall between $11 \%$ and $13 \%$. The college requesting the least demonstrations was the College of Science at $2.7 \%$. Figure 6 shows the types of demonstrations requested. Requests for departmental demonstrations comprised $37.8 \%$ of the total, and demonstrations for classes made up $28.9 \%$. $24.4 \%$ of the requests were from other groups, which included campus administration offices, computer user groups, and demonstrations for external University support groups. $8.9 \%$ opted to combine class demonstrations with departmental demonstrations.

\section{Conclusions}

It is dangerous to draw overgeneralized conclusions concerning the total population from a relatively small body of data; however, certain patterns became apparent from the responses to the "purple monster." The brochure was, from all indications, widely read on campus and did serve its primary purpose of alerting the faculty to the existence of the new system. The relatively high number of returned tearsheets and phoned-in requests did indicate that the brochure had caught the attention of its target audience, enabled the library to gauge what requests were most frequent, and to judge what areas were of most interest to the faculty.

Responses to the brochure indicated that interest in remote access to the system from home and office was high. With the knowledge of this wide interest in remote access, the Reference Division responded by emphasizing remote access instruction during NOTIS training sessions for public services faculty and staff in order to answer telephone queries from users who encountered problems while accessing the system from outside the Library.

The requests for remote access instructions also leaned heavily toward microcomputers with modems, indicating that most were not as interested in hardwired terminals, which are available on campus. The number of calls received at the Reference Desk during the evening requesting assistance with remote access would tend to indicate that many faculty and students are using their home computers to dial into the system. The NOTIS system currently averages 150 dial-in users per day, and has had as many as 300 on peak days.

In studying the data, we noticed that interest in remote access was particularly high among those colleges which have an interest in technology by the nature of their disciplines, both in scientific research, and business applications. Other less technical colleges, such as Education, showed greater interest in individualized instruction sessions.

As libraries become more driven by technology, librarians must not ignore the traditionally heavy users of the library, the Liberal Arts and Education 
faculty. Many of these faculty members are hesitant or uneasy about the encroachment of computers into their book and journal-oriented researches. Liberal Arts faculty are often surprised and pleased to learn that the newer library technologies, which many assume to be almost totally directed toward scientists or business faculty, have much to offer the serious scholar in Liberal Arts. For example, faculty have been glad to discover the keyword and Boolean search capabilities of NOTIS which enable them to narrow searches by language, date, edition, and even publisher.

Faculty have, in the past, frequently been unwilling to receive instruction in the use of online and other computerized sources, as it meant standing out in a public area where their students might observe them. In the case of NOTIS training, faculty were instructed using a NOTIS terminal located in the Reference Division offices, where they could be comfortably seated and be assured of privacy. Giving faculty the chance to receive individualized instruction in a discreet setting should result in a greater willingness on their parts to encourage their students to use NOTIS and other aspects of technology in the library. Demonstrations of the system are another excellent way of reaching these faculty members, and showing them that the online catalog is not to be feared, and may indeed prove beneficial.

Departmental demonstrations gave librarians a chance to contact faculty members who do not come into the library frequently, and offered them the opportunity to learn firsthand about what the new system could do for them, as well as providing a concrete example of remote access at work. Class demonstrations, on the other hand, enabled librarians to reach both students and faculty with the message that the new computer system was available and an improvement on the previous system.

In a different way, demonstrations of the system for audiences not directly connected with the university also prove worthwhile, especially from a public relations standpoint. Such demonstrations for external support groups generated considerable interest in the system, which was presented as a major enhancement to library services and to the educational experience of all students at Texas A\&M. These demonstrations even resulted in the donation of several NOTIS terminals, printers, and cash gifts to the library by interested groups.

As a result of this study, we learned that the Colleges of Liberal Arts and Education need to be specially targeted for training and other outreach activities concerning all aspects of library automation. Other colleges less inclined to use the library, such as Agriculture and Science, have long been areas of concern for library instruction generally and the advent of new technology has provided an opportunity for the library to renew its efforts on their behalf. In the final analysis, the data produced by the study of the responses to the brochure enabled librarians to formulate further plans for instructional outreach concerning the online cata$\log$ to university faculty and researchers.

\section{Appendix}

Colleges responding to the brochure as listed on the graphs:

$\begin{aligned} \mathrm{A} & =\text { Business } \\ \mathbf{B} & =\text { Medicine } \\ \mathbf{C} & =\text { Geosciences } \\ \mathrm{D} & =\text { Engineering } \\ \mathbf{E} & =\text { Architecture } \\ \mathbf{F} & =\text { Liberal Arts } \\ \mathbf{G} & =\text { Education } \\ \mathbf{H} & =\text { Agriculture } \\ \mathbf{I} & =\text { University Administration } \\ \mathbf{J} & =\text { Research Agencies } \\ \mathbf{K} & =\text { Veterinary Medicine } \\ \mathbf{L} & =\text { Science } \\ \mathbf{M} & =\text { Non-University }\end{aligned}$

\section{Gay/Lesbian Book Awards}

The ALA Gay and Lesbian Task Force is calling for nominations for its 1991 Gay/Lesbian Book Awards. Awards are made for both fiction and nonfiction of exceptional merit relating to the gay/ lesbian experience. To be eligible, a book must have been published in calendar year 1990. The awards are not limited to American publications; books published outside the United States and in non-English languages are also eligible.

The awards have been given since 1971, making them the oldest gay and lesbian award in the United States. A committee made up of members of the ALA Gay and Lesbian Task Force decides each year's winners from a list of nominations compiled throughout the year. Any individual or group not affiliated with the publisher of the book being nominated may submit nominations to the chair of the Gay/Lesbian Book Award Committee: Adam L. Schiff, Assistant Science Librarian, University of Colorado at Boulder, Campus Box 184, Boulder, CO 80309-0184; fax, (303) 482-2185; e-mail, schiff_a@cubldr.colorado.edu. A short statement describing why a book is being nominated must accompany the nomination. Nominations must be mailed by December 31, 1990. The award winners will be announced in March 1991. 


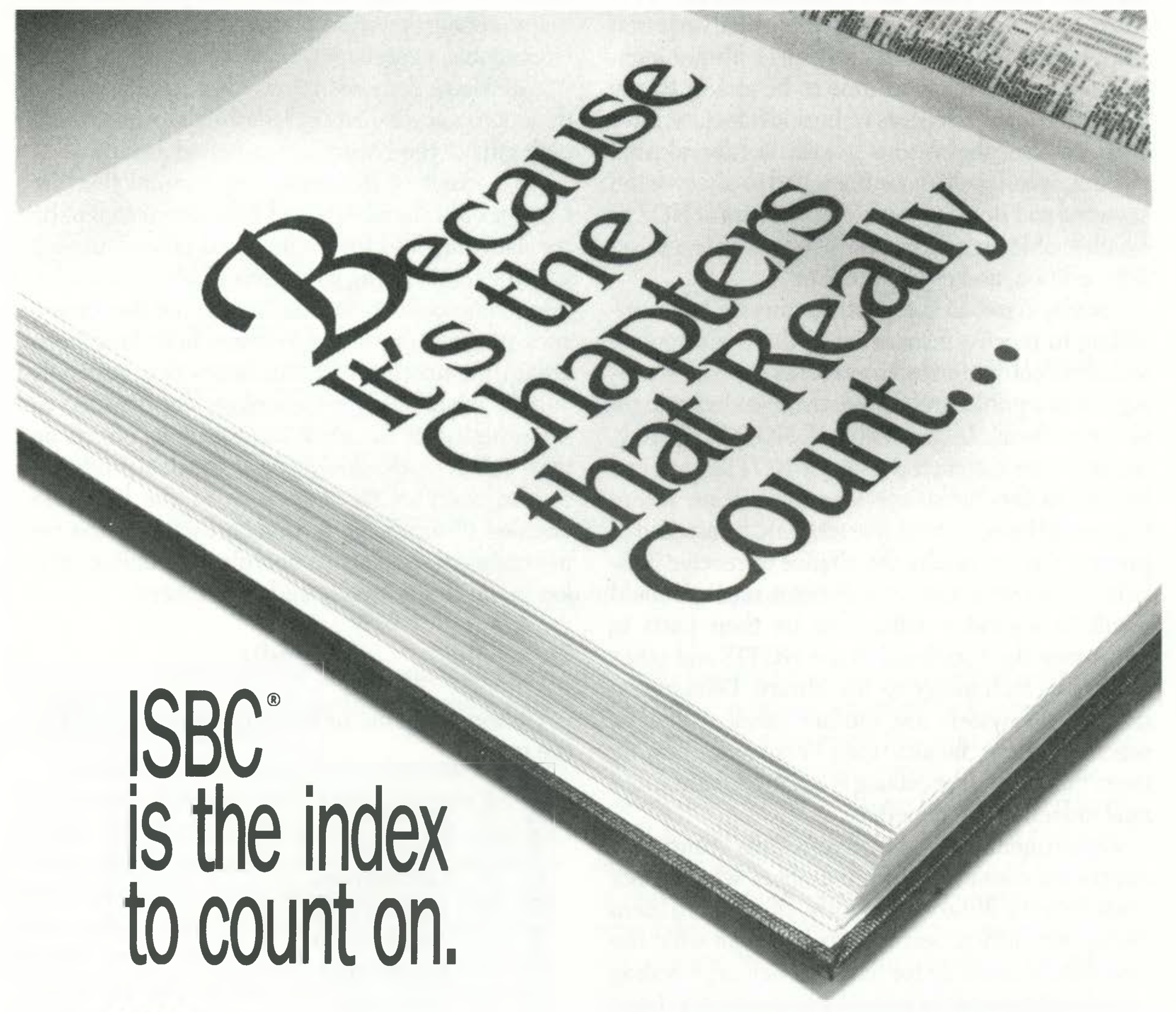

The

he Index to Scientific Book Contents ${ }^{\circledR}$ is the only research tool that indexes scientific books at the individual chapter level.

It covers more than 36,000 chapters from over 2,000 multi-authored books and book series, so your patrons can search the scientific book literature...without looking through all the books.

They can search by author/editor name, book and chapter title words, general book category, author affiliation or author's geographic location. Or they can turn straight to the complete listing of book contents to find the necessary bibliographic information.

For more information or to receive a free quarterly sample issue, call toll-free: 800-336-4474, operator R346 (U.S. and Canada). Or write to one of the addresses below.

\section{ISBC. Count on it for searching scientific books.}

\section{Institute for Scientific Information ${ }^{(1)}$}

3501 Market Street, Philadelphia, PA 19104 USA

European Branch: 132 High Street, Uxbridge, Middlesex UB8 1DP United Kingdom, Telephone: +44-895-70016

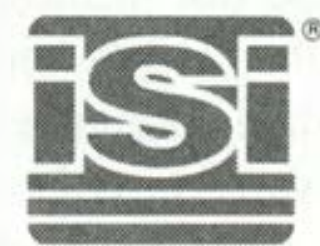

